\title{
Impact of climate change in Switzerland on socioeconomic snow indices
}

\author{
Edgar Schmucki ${ }^{1,2,3} \cdot$ Christoph Marty $^{1}$ - Charles Fierz ${ }^{1} \cdot$ Rolf Weingartner $^{2,3}$. \\ Michael Lehning ${ }^{1,4}$
}

Received: 17 December 2014 / Accepted: 4 November 2015/Published online: 18 November 2015

(C) Springer-Verlag Wien 2015

\begin{abstract}
Snow is a key element for many socioeconomic activities in mountainous regions. Due to the sensitivity of the snow cover to variations of temperature and precipitation, major changes caused by climate change are expected to happen. We analyze the evolution of some key snow indices under future climatic conditions. Ten downscaled and postprocessed climate scenarios from the ENSEMBLES database have been used to feed the physics-based snow model SNOWPACK. The projected snow cover has been calculated for 11 stations representing the diverse climates found in Switzerland. For the first time, such a setup is used to reveal changes in frequently applied snow indices and their implications on various socioeconomic sectors. Toward the end of the twenty-first century, a continuous snow cover is likely only guaranteed at high elevations above $2000 \mathrm{~m}$ a.s.l., whereas at mid elevations (1000-1700 m a.s.1.), roughly $50 \%$ of all winters might be characterized by an ephemeral snow cover. Low elevations (below $500 \mathrm{~m}$ a.s.1.) are projected to experience only 2 days with snowfall per year and show the strongest relative reductions in mean winter snow depth of around
\end{abstract}

Electronic supplementary material The online version of this article (doi:10.1007/s00704-015-1676-7) contains supplementary material, which is available to authorized users.

Christoph Marty

marty@slf.ch

1 WSL Institute for Snow and Avalanche Research SLF, Flüelastrasse 11, 7260 Davos Dorf, Switzerland

2 Institute of Geography, University of Bern, Bern, Switzerland

3 Oeschger Centre for Climate Change Research, University of Bern, Bern, Switzerland

4 CRYOS, School of Architecture, Civil and Environmental Engineering, EPFL, Lausanne, Switzerland
$90 \%$. The range of the mean relative reductions of the snow indices is dominated by uncertainties from different GCMRCM projections and amounts to approximately $30 \%$. Despite these uncertainties, all snow indices show a clear decrease in all scenario periods and the relative reductions increase toward lower elevations. These strong reductions can serve as a basis for policy makers in the fields of tourism, ecology, and hydropower.

\section{Introduction}

Snow is a key feature of mountainous environments because of its high significance for hydrology, vegetation, and the socioeconomic sector, such as winter tourism or hydropower. In the Alps, like in most mountain regions, melting snow and glaciers provide water for heavily populated and farmed areas far down stream even during hot and dry summer months. In Switzerland, hydropower companies use this water to generate a large share of the needed electricity (Beniston 2003). Furthermore, many alpine towns and villages heavily depend on snow, because up to $90 \%$ of their economy is dominated by winter tourism (Abegg et al. 2007). Snow also has a significant influence on the Alpine biota ecology (Krajick 2004). Plants and animals in subalpine and alpine ecosystems strongly respond to changes in snow depth and snowmelt timing (Peng et al. 2010; Wipf et al. 2009). In addition, snow is highly sensitive to climate change because of its proximity to melting point conditions (Haeberli and Beniston 1998).

In today's climate, the seasonal snow cover in the Swiss Alps is primarily influenced by a high year-to-year variability due to variations in the large-scale weather patterns (Scherrer and Appenzeller 2006). Despite the high interannual variability, several studies already showed a significant decrease of snow days in the recent past, especially, but not only, at low-elevation 
stations (Beniston 1997; Laternser and Schneebeli 2003; Marty 2008; Scherrer et al. 2004). It can be assumed that such trends will be amplified by climate change. Zubler et al. (2014) showed with a simple parameterization that the number of days with snowfall in Switzerland may be reduced by up to 1 month between the reference and the scenario periods 2070-2099.

The goal of this study is to go beyond basic statistical extrapolation and use a physics-based snow model together with a full set of high-resolution regional climate models driven by lowresolution global climate models (GCM-RCM model chains) in order to be able to sample the uncertainty of temperature and precipitation projections inherent in global and regional climate models. Unlike in most other similar studies, incoming longwave radiation has also been modified for future climatic conditions, which we showed to be important in a previous study (Schmucki et al. 2014b). Note that the small increase in winter precipitation has almost no effect on the future decrease of the snow cover at stations below $2000 \mathrm{~m}$ a.s.l., compared to the strong increase in air temperature and long-wave radiation (Schmucki et al. 2014b). We derive our results from a stationbased comparison in order to reduce uncertainties introduced by the interpolation process in other studies (Bavay et al. 2013). The applied methods are based on a former work described in Schmucki et al. (2014b). One big asset of an investigation on the snow-climate interaction of socioeconomic relevant snow indices in a region like Switzerland is the fact that several snow-climate zones are represented in the relatively small area of the Swiss Alps. In this study, we therefore concentrate on the evolution of certain snow indices under future climatic conditions. Many societal challenges and sectors such as ecology, water management, hydropower, or tourism depend on climatological conditions (Zubler et al. 2014). In contrast to average snow depth scenarios, these indices contain an additional value for decision-makers, for example when planning investments for tourist infrastructure, protection measures against avalanches, or environmental planning.

The paper is organized as follows: The input data, the delta change approach, the emission scenarios, and the definition of the snow indices used in this study are summarized in Section 2. Section 3.1 shows the changes in mean winter snow depth, followed by the decrease in continuous snow cover (Section 3.2), the decrease in snow days with specific thresholds (Section 3.3), and the decrease in new snow days $>1 \mathrm{~cm}$ (Section 3.4). The results are then discussed in Section 4 and Section 5 gives the most relevant conclusions.

\section{Data and methods}

\subsection{Input data}

We use data from 11 high-quality, automatic meteorological stations to run the physics-based, one-dimensional snow model SNOWPACK (Lehning et al. 2002a, b; Schmucki et al. 2014a). All data were provided by the Federal Office of Meteorology MeteoSwiss and the WSL Institute of Snow and Avalanche Research, SLF Davos. The 11 stations are shown in Table 1 together with their coordinates, elevations, and snow cover regimes. We divide these 11 stations into three elevation ranges and snow cover regimes: Stations below $500 \mathrm{~m}$ a.s.l. (Payerne and Kloten) belong to the ephemeral snow cover regime and are defined as low-elevation stations. Stations between 1000 and $1700 \mathrm{~m}$ a.s.l. belong to the Alpine snow cover regime and are defined as mid-elevation stations. Note that these stations lie in very distinct climatic regions in Switzerland, mostly affected by different precipitation regimes. The only station above $2000 \mathrm{~m}$ a.s.l. is the highelevation station Weissfluhjoch at $2540 \mathrm{~m}$ a.s.l. and belongs to the high Alpine snow cover regime. Note that Weissfluhjoch represents the mean snow depth of the Alpine network of automatic weather stations located between 2000 and $3000 \mathrm{~m}$ a.s.l. (Egli 2008; Marty and Meister 2012) despite the fact that this elevation zone exhibits a very high spatial variability of snow depth and snowfall (Blanchet and Lehning 2010; Blanchet et al. 2009). The geographical distribution of all selected stations is shown in Fig. 1 of Schmucki et al. (2014b).

The meteorological input parameters are air temperature, relative humidity, wind speed and direction, incoming short-wave radiation, and precipitation rate; all parameters have a temporal resolution of $1 \mathrm{~h}$. Precipitation is corrected for gauge undercatch (Hamon 1973) and incoming long-wave radiation (usually not measured by automatic weather stations) is parameterized using a combination of the Dilley and O'Brien (1998) clear sky algorithm with the Unsworth and Monteith (1975) cloud correction algorithm (see Schmucki et al. 2014a, b). Data from 1984 to 2010 served as the reference period (27 years). Analysis has shown that snow depth can be reproduced well in the reference period with errors in the order of $9 \%$ (Schmucki et al. 2014b). It is noteworthy that no site-specific calibration has been performed (e.g., with parameters such as roughness length) which further increases the robustness of the model results.

\subsection{Climate scenarios and delta change method}

The climate scenario data were obtained from the Swiss Climate Change Scenarios report CH2011 (2011). The postprocessed output of this report provides the mean annual cycle of temperature and precipitation changes of $10 \mathrm{GCM}$ RCM model chains from the ENSEMBLES project (van der Linden and Mitchell 2009) in daily resolution for station locations in Switzerland (Bosshard et al. 2011). We use the IPCC fourth assessment A1B and A2 emission scenarios (IPCC 2007) which are described below. The more recent fifth assessment report (IPCC 2014) has quantitatively confirmed the results of the earlier report, i.e., the projected climate change based on representative concentration pathways 
Table 1 Meteorological stations used in this study (adapted from Schmucki et al. 2014b)

\begin{tabular}{lllll}
\hline Station & ID & Coordinates (latitude ${ }^{\circ}$ N/longitude ${ }^{\circ}$ E) & Elevation (m a.s.l.) & Snow cover regime \\
\hline Weissfluhjoch & WFJ & $46.8 / 9.8$ & 2540 & High Alpine \\
San Bernardino & SBE & $46.5 / 9.2$ & 1640 & Alpine \\
Zermatt & ZER & $46.0 / 7.8$ & 1640 & Alpine \\
Davos & DAV & $46.8 / 9.9$ & 1590 & Alpine \\
Montana & MVE & $46.3 / 7.5$ & 1430 & Alpine \\
Ulrichen & ULR & $46.5 / 8.3$ & 1350 & Alpine \\
Adelboden & ABO & $46.5 / 7.6$ & 1320 & Alpine \\
Scuol & SCU & $46.8 / 10.3$ & 1300 & Alpine \\
Engelberg & ENG & $46.8 / 8.4$ & 1040 & Alpine \\
Payerne & PAY & $46.8 / 7.0$ & 490 & Ephemeral \\
Kloten & KLO & $47.5 / 8.5$ & 430 & Ephemeral \\
\hline
\end{tabular}

(RCPs) (Moss et al. 2010; van Vuuren et al. 2011) is similar to the fourth assessment report in both patterns and magnitude, after accounting for scenario differences.

- The A1B emission scenario describes a future world of very rapid economic growth, global population that peaks in mid-century and declines thereafter, and the rapid introduction of new and more efficient technologies. The use of fossil-intensive and nonfossil energy sources is assumed to be balanced. Toward the end of the century, global mean temperature is increased by roughly $2.8^{\circ} \mathrm{C}$ compared to the reference period 1980-1999; therefore, this emission scenario represents approximately the mean temperature increase between the various emission scenarios.

- The A2 emission scenario describes a very heterogeneous world. Fertility patterns across regions converge very slowly, which results in continuously increasing population. Economic development is primarily regionally oriented, and per capita economic growth and technological changes are more fragmented and slower than in other emission scenarios. Toward the end of the century, global mean temperature is increased by roughly $3.4{ }^{\circ} \mathrm{C}$ compared to the reference period 1980-1999, i.e., the temperature increase is higher than in the A1B emission scenario.

As in Schmucki et al. (2014b), the scenario periods cover three 30-year time slots: 2020-2049 (referred to hereafter as 2035), 2045-2074 (hereafter 2060), and 2070-2099 (hereafter 2085). Please note that our reference period (1984-2010) slightly deviates from the reference period of the CH2011 report (1980-2009) because at some stations high-quality measurements are only available from 1983 onwards. For future temperature, the daily delta change signal is added to the observed hourly time series of temperature, whereas for future precipitation the daily delta change signal is multiplied with the observed hourly time series of precipitation. The threshold distinguishing solid from liquid precipitation was set to $1.2^{\circ} \mathrm{C}$ for all stations. For a boxplot of temperature and precipitation changes at the 11 stations used in this study (A1B emission scenario only), please see Fig. 3 in Schmucki et al. (2014b). In summary, the GCM-RCM model chains show a consistent winter (November to April) temperature increase between 2.7 and $3.1{ }^{\circ} \mathrm{C}$ for the 11 stations toward the end of the century and increases in winter precipitation between 0 and $17 \%$ in the A1B emission scenario. In the A2 emission scenario, the increase in winter precipitation is similar (0-20\%) but the winter temperature increase $\left(3.1-3.6^{\circ} \mathrm{C}\right)$ toward the end of the century is higher (roughly $0.5^{\circ} \mathrm{C}$ ) compared to the $\mathrm{A} 1 \mathrm{~B}$ emission scenario. The projected temperature increase is therefore similar to the increase in mean global temperature, but it is noteworthy that the observed temperature trend for Switzerland is substantially higher than the temperature trend of the northern hemisphere (Ceppi et al. 2012). Another difficulty in applying the delta change method lies in the assumption that natural variability is preserved for future climatic conditions, i.e., there are no changes in the extremes. This has an impact on the accuracy of the predictions (Maraun 2013), but since the downscaled delta change values have been specifically issued for our investigation area (Bosshard et al., 2011), we chose to work with those values. In addition, delta change values are less sensitive to model errors of individual GCM-RCMs (Schmucki et al. 2014b and references therein), but their use is only appropriate assuming stationary seasonality. Furthermore, the very small precipitation changes for many scenario periods and seasons are actually within the range of natural climate variability and cannot be considered as a forced climate change signal (Fischer et al. 2012). Incoming long-wave radiation is a crucial component of the energy balance and highly temperature dependent (Marty and Philipona 2000) but is often neglected in snow modeling studies. We therefore also modified incoming long-wave radiation through the temperature projections. On average, the increase of ILWR amounts to 6,11 , and $16 \mathrm{~W} \mathrm{~m}^{-2}$ over the 2035, 2060, 
and 2085 scenario periods, respectively (Schmucki et al. $2014 b$ ). Note that the projected small increase in winter precipitation has almost no effect at mid-elevation stations but incoming long-wave radiation has an important effect (Schmucki et al. 2014b). In summary, temperature, precipitation, and parameterized incoming long-wave radiation have been perturbed through the output of 10 individual GCMRCMs for future scenario calculations, whereas relative humidity, wind, and incoming short-wave radiation have been kept unchanged.

\subsection{Snow indices}

Climate indices simplify the interpretation of climate change signals on society, economy, and ecology. Here, some key snow indices are considered, which are relevant to socioeconomic sectors such as water management, ecology, tourism, or road maintenance. Furthermore, a selection criterion for the indices was that the errors (as in snow depth) between the modeled and observed values in the reference period are on average about $10 \%$. This helps to obtain robust estimates of future changes in these indices. For a detailed overview of the errors of the snow indices at the different stations, please see Table 2. The indices represent annual mean values for the reference and scenario periods, whereby a year is defined as the 12 months from September to August. The following snow indices are therefore considered for this study:

- Mean winter snow depth: Defined as the mean snow depth per year in the winter months December, January, and February. The reduction is expressed as relative change (\%). This index allows comparing the absolute snow depth among locations and has widespread use also in similar studies. It is also highly correlated to the snow water equivalent (Schmucki et al. 2014b), which is usually used in hydrological studies.

- Fraction of winters with continuous snow cover: An individual winter is defined as continuous, if the duration of continuous snow cover with a threshold above $5 \mathrm{~cm}$ lasts at least 30 days. This index was considered because locations with winter tourism currently experience a continuous seasonal snow cover, i.e., a permanent snow cover forms at latest in December and disappears at earliest beginning of March.

- Snow days (SD): Number of days with a snow depth larger than $5 \mathrm{~cm}$ (SD5) or $50 \mathrm{~cm}$ (SD50) per year. These indices count the number of days with "enough" snow. The threshold depends on the activity. More than $5 \mathrm{~cm}$ of snow (SD5) are necessary for sledding or cross-country skiing. This threshold is also a good hydrological indicator for the number of days where snow for runoff is available. The threshold of $50 \mathrm{~cm}$ of snow (SD50) is important for skiing on rough terrain (e.g., rocky slopes) or for management of forests in potential avalanche release areas.

- New snow days: Number of days per year with a height of new snow greater than $1 \mathrm{~cm}(\mathrm{HN} 1)$. This index is of relevance for snow removal managers or powder snow seeking freeskiers.

\section{Results}

The following figures and tables demonstrate that the relative reductions in the snow indices are similar for both emission scenarios. The A1B emission scenario shows slightly higher

Table 2 Mean bias error (MBE) and mean percentage error (MPE) in SD5, SD50, HN1, and mean DJF snow depth for the reference period 1984 2010 at the 11 stations used in this study. Note that Payerne and Kloten do not have any snow days $>50 \mathrm{~cm}$ on average

\begin{tabular}{|c|c|c|c|c|c|c|c|c|}
\hline & \multicolumn{2}{|l|}{ SD5 } & \multicolumn{2}{|l|}{ SD50 } & \multicolumn{2}{|l|}{ HN1 } & \multicolumn{2}{|c|}{ Mean HS DJF } \\
\hline & MBE [days] & MPE [\%] & MBE [days] & MPE [\%] & MBE [days] & MPE [\%] & $\mathrm{MBE}[\mathrm{cm}]$ & MPE $[\%]$ \\
\hline WFJ & 18.3 & 6.9 & 4.2 & 2.0 & 17.6 & 17.7 & -2.7 & -2.1 \\
\hline SBE & 4.3 & 2.8 & -2.7 & -3.0 & 9.3 & 21.9 & -3.4 & -5.5 \\
\hline ZER & 1.6 & 1.2 & -14.7 & -31.9 & 0.9 & 2.4 & -8.3 & -20.0 \\
\hline DAV & 5.9 & 3.8 & 5.1 & 7.1 & 2.7 & 5.1 & -0.5 & -1.0 \\
\hline MVE & 14.3 & 11.3 & -6.0 & -8.9 & 3.1 & 7.6 & -5.9 & -11.0 \\
\hline ULR & 11.3 & 7.3 & 16.8 & 17.3 & 10.8 & 23.3 & 7.2 & 10.0 \\
\hline $\mathrm{ABO}$ & 13.6 & 13.4 & -10.4 & -61.1 & -4.6 & -8.8 & -2.8 & -12.5 \\
\hline $\mathrm{SCU}$ & 21.3 & 20.9 & 3.3 & 20.0 & 5.9 & 23.4 & 3.1 & 11.3 \\
\hline ENG & 20.3 & 19.8 & 0.8 & 4.2 & 4.4 & 10.6 & 2.0 & 8.3 \\
\hline PAY & -0.6 & -7.2 & N/A & N/A & 2.3 & 34.2 & 0.0 & 2.8 \\
\hline KLO & -2.8 & -23.7 & N/A & N/A & 1.3 & 13.5 & -0.5 & -31.6 \\
\hline
\end{tabular}

$N / A$ not applicable 
reductions in the first two scenario periods, whereas for the 2085 scenario period, the A2 emission scenario shows higher relative reductions consistent with the respective temperature changes. For the sake of readability, we only describe the results of the A1B emission scenario in the text.

\subsection{Changes in mean winter snow depth}

Table 3 shows the reference and projected mean winter snow depth (December-January-February, DJF) for the three scenario periods 2035, 2060, and 2085 for all 11 stations. In Fig. 1, only three sample stations representing high, mid, and low elevations are shown. Not surprisingly, the high-elevation station Weissfluhjoch is least affected by predicted climate change. There is almost no change visible in the first scenario period $(-3 \%)$ and only minor changes in the 2060 scenario period $(-14 \%)$. Toward the end of the century, however, reductions grow considerably and amount to $23 \%$, but the mean snow depth remains relatively high at roughly $95 \mathrm{~cm}$.

Mid elevations (see Fig. 1 with San Bernardino as an example) already show a pronounced decrease of mean winter snow depth between 26 and $41 \%$ (mean of $34 \%$ ) in the 2035 scenario period, steadily increasing to $49-70 \%$ (mean of $60 \%$ ) in the 2060 scenario period. Reductions are very high in the 2085 scenario period, ranging from 66 to $81 \%$ (mean of $74 \%)$. Moreover, all of these mid-elevation stations have a mean winter snow depth of less than $20 \mathrm{~cm}$ toward the end of the century.

The low-elevation stations show the strongest (relative) reduction in mean winter snow depth in the near future (59\%). For the 2060 scenario period, the reductions amount to $78 \%$, whereas in the 2085 scenario period, reductions are only slightly higher (roughly $85 \%$ ) than for mid-elevation stations.

In addition to the mean winter snow depth, Fig. 2 shows the simulated daily mean snow depth for the reference period and the three scenario periods at Weissfluhjoch and San Bernardino. San Bernardino represents a typical station of the Southern Alpine rim in Switzerland. We included this figure in order to provide information considering changes in the dynamics describing buildup and depletion of the snowpack. In the 2035 scenario period, precipitation is partly able to compensate for the projected temperature increase at the high-elevation station Weissfluhjoch. The spread of results obtained with input from the different climate models is small but increases toward the end of the century. The depletion of the snowpack is more affected than the buildup at Weissfluhjoch because the temperatures during buildup in the reference period are much colder at this high-elevation station compared to mid-elevation stations. Therefore, projected higher temperatures have a weaker influence on the buildup than on the depletion on the snowpack, where temperatures are already close to melting point in the reference period. In contrast, at the mid-elevation station San Bernardino, mean daily snow depth is significantly impacted during buildup and depletion of the snowpack even in the near future, since temperatures are closer to the melting point during both buildup and depletion in the reference period. In addition, this mid-elevation station has the highest spread of the projected winter precipitation and temperature changes of individual GCM-RCMs compared to the other stations (cf. Fig. 3 in Schmucki et al. 2014b). Moreover, San Bernardino shows the highest median temperature increase of the 11 stations used in this study. In general, stations located in the Southern Alpine rim of Switzerland are typically affected by an increase in mean DJF precipitation (CH2011 2011). Note that Fig. 2 cannot provide any information concerning changes in continuous snow cover shown below.

\subsection{Decrease in continuous snow cover}

We investigate changes in continuous snow cover (as defined in Section 2.3) by calculating the percentage of winters with continuous snow cover in the reference and the three scenario periods. Figure 3 shows the decrease of winters with continuous snow cover at nine stations used in this study. Note that the low-elevation stations are excluded, as they are already ephemeral in the reference period. The high-elevation station Weissfluhjoch is the only station which preserves a continuous snow cover through all three scenario periods. In the reference period, all stations have a continuous snow cover each winter except Engelberg (1040 m a.s.1.) and Adelboden (1320 m a.s.l.), where the percentage of winters with ephemeral snow cover amounts to 4 and $7 \%$, respectively. In the 2035 scenario period, the mid-elevation stations show a decrease of continuous snow cover between 4 and $22 \%$, except in Davos and Ulrichen, where a continuous snow cover exists in all winters. In the 2060 scenario period, the decrease of winters with continuous snow cover is more pronounced but varies significantly between stations. The highest relative change from continuous to ephemeral (33 to $52 \%$ ) is found at the lower lying mid-elevation stations (Adelboden, Scuol, and Engelberg). The remaining stations (San Bernardino, Zermatt, Davos, Montana, and Ulrichen) show reductions in winters with continuous snow cover between 7 and $30 \%$. By the end of the century, half of the stations have a predominantly ephemeral snow cover regime, but the spread in relative reductions between the stations remains high $(37 \%)$ and differences between the $\mathrm{A} 1 \mathrm{~B}$ and $\mathrm{A} 2$ emission scenarios get considerable larger.

\subsection{Decrease in snow days}

The number of snow days was investigated for thresholds of 1 , 5,30 , and $50 \mathrm{~cm}$. These are common thresholds used for different snow activities (Abegg et al. 2007; Beniston 1997; 
Table 3 Mean winter snow depth (DJF) in centimeters as well as relative and absolute decrease of the mean winter snow depth in percent and centimeters for the reference period (REF) 1984 2010 as well as the three scenario periods 2035, 2060, and 2085 for the A1B and $\mathrm{A} 2$ emission scenarios

\begin{tabular}{|c|c|c|c|c|c|c|c|}
\hline & \multirow[t]{2}{*}{ REF } & \multicolumn{2}{|l|}{2035} & \multicolumn{2}{|l|}{2060} & \multicolumn{2}{|l|}{2085} \\
\hline & & A1B & A2 & A1B & A2 & A1B & A2 \\
\hline \multicolumn{8}{|l|}{ WFJ } \\
\hline Mean DJF snow depth $[\mathrm{cm}]$ & 126 & 122 & 122 & 109 & 109 & 97 & 89 \\
\hline$\Delta$ snow depth $[\%]$ & & -3 & -3 & -14 & -14 & -23 & -29 \\
\hline$\Delta$ snow depth $[\mathrm{cm}]$ & & -4 & -4 & -17 & -17 & -29 & -37 \\
\hline \multicolumn{8}{|l|}{ SBE } \\
\hline Mean DJF snow depth [cm] & 59 & 37 & 39 & 24 & 24 & 14 & 10 \\
\hline$\Delta$ snow depth $[\%]$ & & -37 & -34 & -59 & -59 & -77 & -83 \\
\hline$\Delta$ snow depth $[\mathrm{cm}]$ & & -22 & -20 & -35 & -35 & -45 & -48 \\
\hline \multicolumn{8}{|l|}{ ZER } \\
\hline Mean DJF snow depth [cm] & 33 & 22 & 23 & 14 & 15 & 8 & 6 \\
\hline$\Delta$ snow depth $[\%]$ & & -33 & -30 & -57 & -57 & -75 & -82 \\
\hline$\Delta$ snow depth $[\mathrm{cm}]$ & & -11 & -10 & -19 & -19 & -25 & -27 \\
\hline \multicolumn{8}{|l|}{ DAV } \\
\hline Mean DJF snow depth $[\mathrm{cm}]$ & 52 & 39 & 40 & 26 & 26 & 18 & 14 \\
\hline$\Delta$ snow depth $[\%]$ & & -26 & -23 & -49 & -49 & -66 & -74 \\
\hline$\Delta$ snow depth $[\mathrm{cm}]$ & & -13 & -12 & -26 & -25 & -34 & -38 \\
\hline \multicolumn{8}{|l|}{ MVE } \\
\hline Mean DJF snow depth $[\mathrm{cm}]$ & 48 & 33 & 35 & 20 & 20 & 13 & 10 \\
\hline$\Delta$ snow depth $[\%]$ & & -30 & -27 & -59 & -58 & -73 & -80 \\
\hline$\Delta$ snow depth $[\mathrm{cm}]$ & & -14 & -13 & -28 & -28 & -35 & -38 \\
\hline \multicolumn{8}{|l|}{ ULR } \\
\hline Mean DJF snow depth $[\mathrm{cm}]$ & 79 & 50 & 53 & 32 & 32 & 19 & 14 \\
\hline$\Delta$ snow depth $[\%]$ & & -36 & -33 & -60 & -59 & -75 & -82 \\
\hline$\Delta$ snow depth $[\mathrm{cm}]$ & & -29 & -26 & -47 & -46 & -59 & -64 \\
\hline \multicolumn{8}{|l|}{$\mathrm{ABO}$} \\
\hline Mean DJF snow depth $[\mathrm{cm}]$ & 20 & 13 & 14 & 8 & 8 & 6 & 4 \\
\hline$\Delta$ snow depth $[\%]$ & & -34 & -31 & -61 & -60 & -72 & -78 \\
\hline$\Delta$ snow depth $[\mathrm{cm}]$ & & -7 & -6 & -12 & -12 & -14 & -15 \\
\hline \multicolumn{8}{|l|}{ SCU } \\
\hline Mean DJF snow depth $[\mathrm{cm}]$ & 31 & 19 & 20 & 11 & 11 & 7 & 6 \\
\hline$\Delta$ snow depth $[\%]$ & & -37 & -34 & -63 & -63 & -76 & -82 \\
\hline$\Delta$ snow depth $[\mathrm{cm}]$ & & -11 & -11 & -19 & -19 & -23 & 25 \\
\hline \multicolumn{8}{|l|}{ ENG } \\
\hline Mean DJF snow depth $[\mathrm{cm}]$ & 26 & 15 & 16 & 8 & 8 & 5 & 4 \\
\hline$\Delta$ snow depth $[\%]$ & & -41 & -38 & -70 & -69 & -81 & -85 \\
\hline$\Delta$ snow depth $[\mathrm{cm}]$ & & -11 & -10 & -18 & -18 & -21 & -22 \\
\hline \multicolumn{8}{|l|}{ PAY } \\
\hline Mean DJF snow depth [cm] & 1 & 1 & 1 & 0 & 0 & 0 & 0 \\
\hline$\Delta$ snow depth $[\%]$ & & -59 & -54 & -78 & -78 & -85 & -86 \\
\hline$\Delta$ snow depth $[\mathrm{cm}]$ & & -1 & -1 & -1 & -1 & -1 & -1 \\
\hline \multicolumn{8}{|l|}{ KLO } \\
\hline Mean DJF snow depth [cm] & 1 & 0 & 1 & 0 & 0 & 0 & 0 \\
\hline$\Delta$ snow depth $[\%]$ & & -59 & -54 & -78 & -78 & -84 & -87 \\
\hline$\Delta$ snow depth $[\mathrm{cm}]$ & & -1 & -1 & -1 & -1 & -1 & -1 \\
\hline
\end{tabular}

Marty 2008). However, we only show the results for SD5 and SD50 (Fig. 4), because the general development was very similar in SD1 and SD30, respectively. Note that the figure for SD1 and SD30 is provided as an Electronic supplementary 


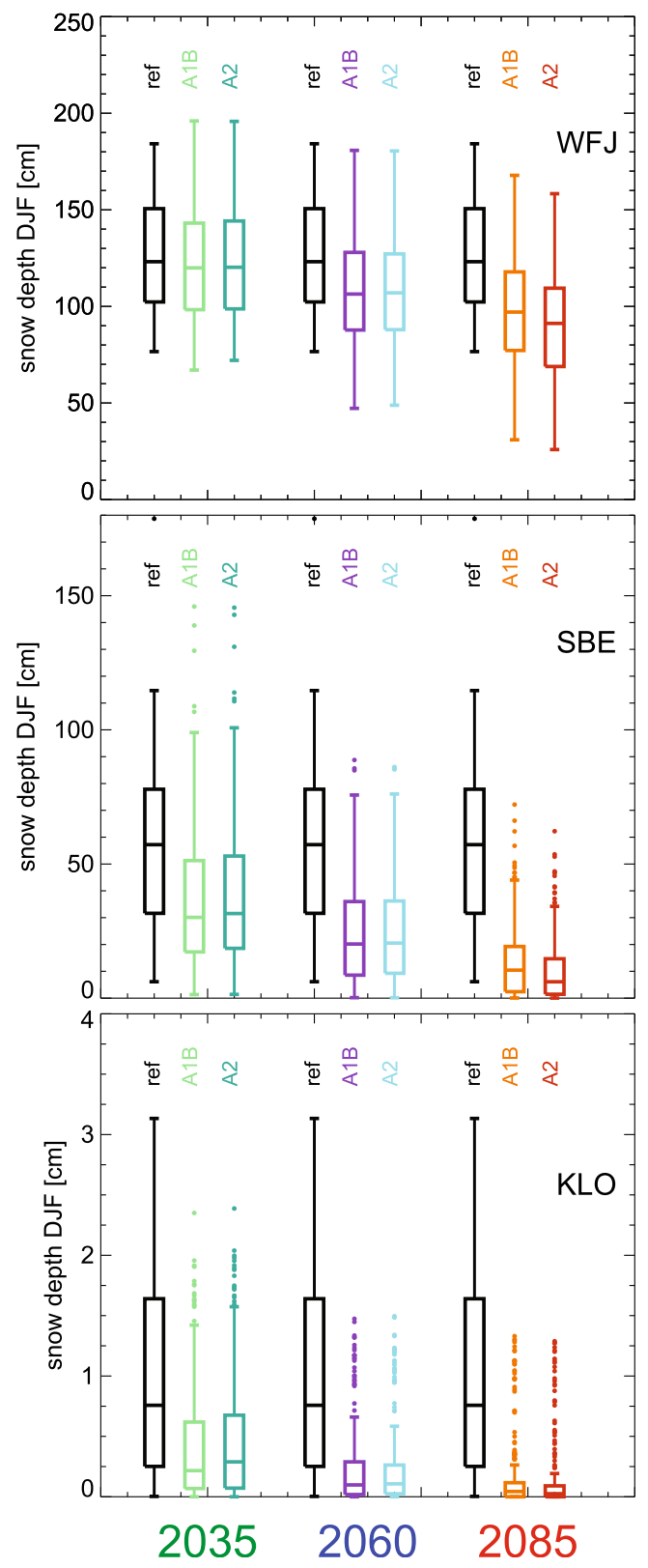

Fig. 1 Interannual mixed with intermodel variability of mean winter (DJF) snow depth in centimeters for the reference period (black) as well as for the three scenario periods 2035 (green), 2060 (blue), and 2085 (red) in the $\mathrm{A} 1 \mathrm{~B}$ and $\mathrm{A} 2$ emission scenarios for high elevations (Weissfluhjoch), mid elevations (San Bernardino), and low elevations (Kloten). The whiskers are defined as the minimum or maximum value, if they do not exceed 1.5 times the interquartile range (IQR). Otherwise, the whiskers are equal to 1.5 times the IQR and the outliers are represented as dots. Note that the first boxplot (ref) is based on the reference period and does thus not contain any model variability

material. Within this subchapter, we first concentrate on the mean reductions at high elevations, followed by changes at mid and low elevations. Uncertainties induced by different climate change projections from individual GCM-RCM model chains are shown at the end of this subchapter.
The smallest relative reductions in snow days are found at the high-elevation station Weissfluhjoch. Relative reductions in the 2035 and 2060 scenario periods do not vary significantly between different thresholds and are in the order of 8 and $16 \%$, respectively. For the 2085 scenario period, relative reductions amount to 21 and $26 \%$ for SD5 and SD50, respectively. Even with the high threshold of $50 \mathrm{~cm}$, SD50 is still high at 161 days at this high-elevation station. Absolute reductions in snow days amount to 60 days for the 2085 scenario period, consistently for the two different thresholds. Concerning mid elevations, the relative reductions in SD5 are in the order of 20,40 , and $60 \%$ for the 2035,2060 , and 2085 scenario periods, respectively.

For SD50, the highest reduction of SD50 can be found at the stations where the number of SD50 is already low in the reference period (Zermatt, Scuol, Adelboden, and Engelberg). These stations are clearly separated from the remaining midelevation stations. The relative reductions in SD50 at Zermatt, Adelboden, Scuol, and Engelberg are in the order of 65, 95, and $100 \%$ for 2035, 2060, and 2085, respectively. Therefore, these stations will very likely not have snow depths exceeding $50 \mathrm{~cm}$ toward the end of the century. The remaining midelevation stations (San Bernardino, Davos, Montana, and Ulrichen) show a strong decrease in SD50 as well (40, 75, and $90 \%$ for 2035, 2060, and 2085, respectively). On average, these stations are projected to only experience 10 snow days $>50 \mathrm{~cm}$ per year toward the end of the century. Note the distinct stepwise decline toward the end of the century in the number of SD50 and their relative reductions. Days with high snow depths are already strongly reduced in the 2060 scenario period; therefore, the relative (and absolute) reductions between the 2060 and 2085 scenario periods are lower compared to the reductions between the 2035 and 2060 scenario periods.

At the low-elevation stations Payerne and Kloten, relative reductions in SD5 are highest compared to the other elevations in the order of 65,85 , and $90 \%$ for 2035, 2060, and 2085, respectively. SD5 is therefore on average reduced from 10 days per year to 1 day per year. The stepwise decrease in the relative reductions between the 2060 and 2085 scenario period is very pronounced since the average SD5 is already low ( 2 days per year) in the 2060 scenario period. Note that on average low elevations do not experience snow days over $50 \mathrm{~cm}$ in the reference period. Therefore, the low-elevation stations are excluded from the SD50 panel in Fig. 4.

The reductions shown above only describe the mean decrease and do not account for interannual and/or inter-GCM/ RCM variability. We therefore show in Fig. 5 the mean decrease of SD5 obtained with input from the individual GCMRCM model chains (colors within the gray band) as well as the interannual and inter-GCM/RCM variability as shown in the boxplots for Davos and Engelberg. The range of the relative reductions between individual GCM-RCMs is high and in the order of $26 \%$ for Davos and $33 \%$ for Engelberg. As can 
Fig. 2 Simulated daily mean snow depth for the reference period 1983-2010 (red) and for the scenario periods (colors within the gray band) 2035 (top), 2060 (middle), and 2085 (bottom) for Weissfluhjoch (left) and San Bernardino (right). Note the different scaling of the $y$-axis between these two stations
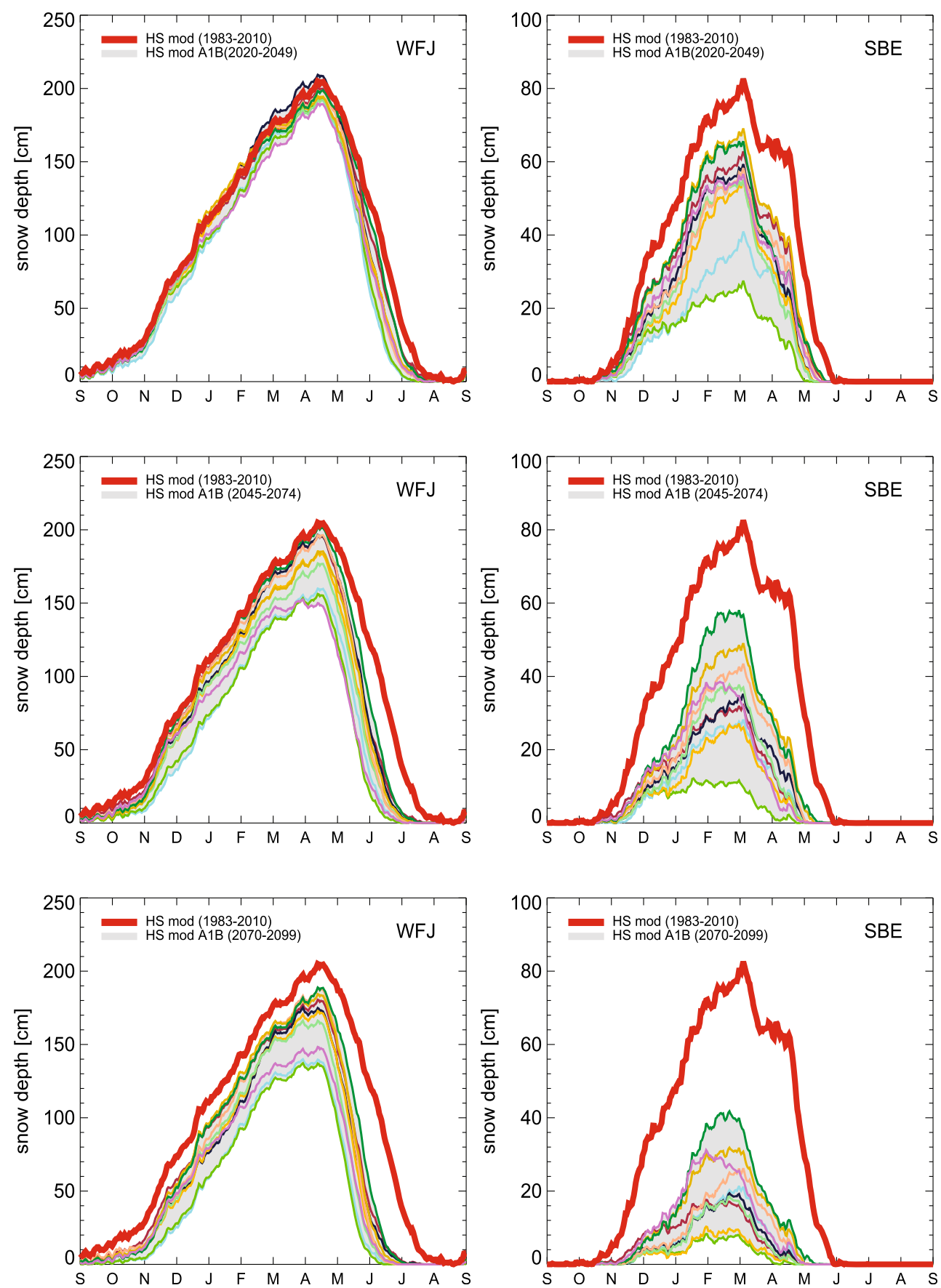

be seen in the boxplots, what would be considered a snowsparse winter of today's climate is projected to become quite average or even snow abundant under future climate conditions. Note that the whiskers of the boxplots do not provide much information concerning the decrease of snow indices because these reductions can emerge from single models in single years. Therefore, the interquantile range or the mean decrease of individual models is a much better indicator for the expected decrease but the whiskers help to understand variability. The interquantile range toward the end of the century is generally higher than in the reference period at high- and mid-elevation stations, but much lower at low elevations because SD5 is strongly reduced at these elevations.

In addition, Table 4 shows the intermodel range of the relative decrease of SD5, SD50, and $\mathrm{HN} 1$ for all three scenario periods in the A1B emission scenario. The range of the relative decrease in SD50 is generally higher compared to SD5 except in the last scenario period, where SD50 is already reduced to a large extent and the influence of different temperature projections becomes weaker. In contrast, the different temperature projections have a large influence on the decrease of SD50 in the first two scenario periods. 


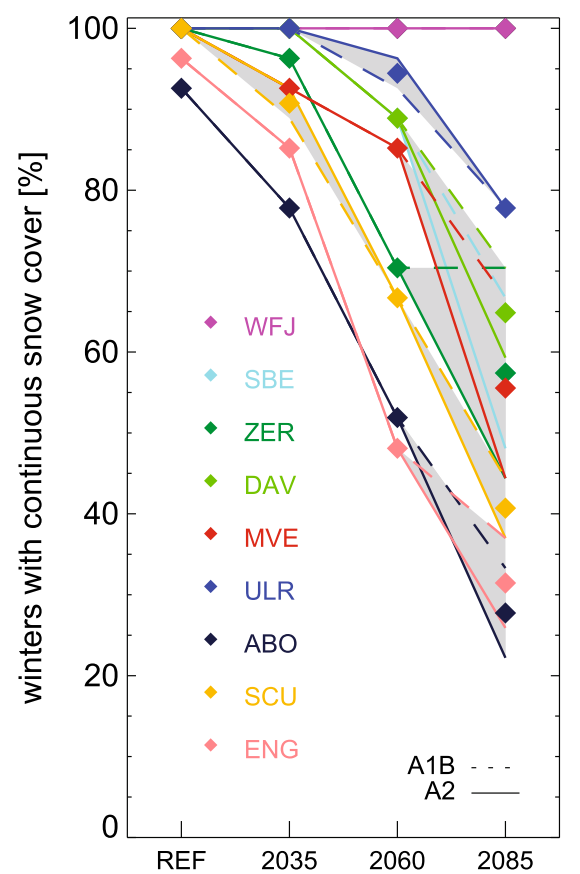

Fig. 3 Percentage of winters with continuous snow cover for the reference period $(R E F)$ and the three scenario periods 2035, 2060, and 2085. The dashed line corresponds to the A1B emission scenario, whereas the solid line corresponds to the A2 emission scenario. The diamond symbol represents the mean between these two scenarios. The low-elevation stations Payerne and Kloten are already ephemeral in the reference period

\subsection{Decrease in new snow days}

As can be seen in Fig. 6, absolute reductions in days with snowfall are highest at the high-elevation station Weissfluhjoch for the 2085 scenario period (30 days), but the relative reductions are lowest here $(26 \%)$. Concerning mid-elevation stations, the lowest reductions can be found at Davos with relative reductions of 16, 30 , and $41 \%$ for the 2035, 2060, and 2085 scenario periods, respectively. For the rest of the mid-elevation stations, the relative reductions are quite similar, ranging between 17-24, 38-46, and 49-59 \% for the 2035, 2060, and 2085 scenario periods, respectively. As for the reduction of snow days, the relative reductions are highest at the low-elevation stations, amounting to approximately $75 \%$ for the 2085 scenario period. On average, these low elevations are projected to experience only 2 days with snowfall per year toward the end of the century.

Concerning absolute values, the number of days with snowfall is reduced by 30,24 , and 8 days for high, mid, and low elevations, respectively. As in SD5 and SD50, Table 4 provides information about the range of relative decreases in HN1 between individual GCM-RCMs, which is in the order of $25 \%$ at mid and low elevations and $15 \%$ at high elevations.

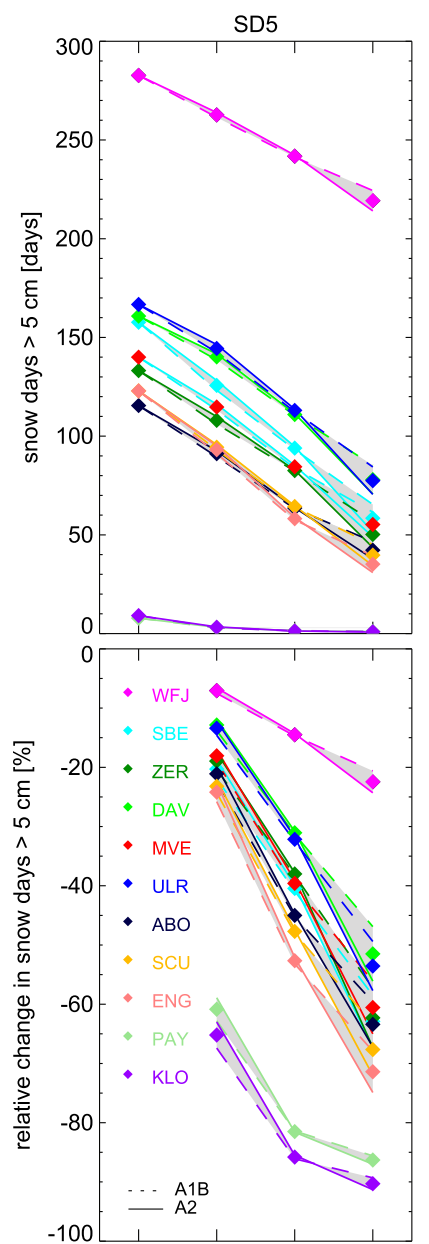

REF 203520602085

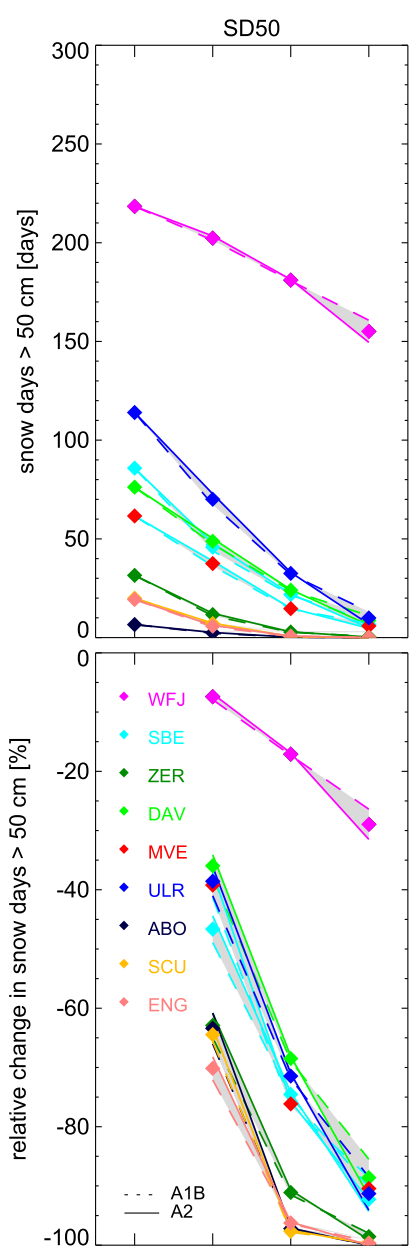

REF 203520602085

Fig. 4 Absolute mean annual number of days (top) and relative changes thereof (bottom) with a snow depth larger than $5 \mathrm{~cm}(S D 5)$ and $50 \mathrm{~cm}$ $(S D 50)$ for the reference period $(R E F)$ and the three scenario periods 2035, 2060, and 2085. The dashed line corresponds to the A1B emission scenario, whereas the solid line corresponds to the A2 emission scenario. The diamond symbol represents the mean between these two scenarios

\section{Discussion}

\subsection{Impact on socioeconomic sectors}

The analysis shows that we can expect drastic reductions in all snow indices considered toward the end of the century. These relative and absolute reductions have high implications for service providers such as winter tourism, water management, winter road maintenance, or forest management. In the following, the reductions of the snow indices and their implication on various socioeconomic sectors as well as the uncertainty caused by the different GCM-RCM model chains are discussed.

Winter tourism is the main economic sector in many Alpine valleys. In Switzerland, the mean winter revenue (2009-2013) from passenger transportation alone is US\$ 800 million (STV 2014). This business is among others impacted by climate 
Fig. 5 Absolute and relative changes of snow days $>5 \mathrm{~cm}$ in Davos (left) and Engelberg (right) from the reference period $(R E F)$ and the three scenario periods 2035,2060 , and 2085. The colors within the gray band correspond to model runs obtained from the perturbed input of individual RCMs, whereas the dashed black line corresponds to the multimodel mean. The whiskers are defined as the minimum or maximum value, if they do not exceed 1.5 times the interquartile range (IQR). Otherwise, the whiskers are equal to 1.5 times the IQR and outliers are represented as dots. Note that the first boxplot $(R E F)$ is based on the reference period and does thus not contain any model variability
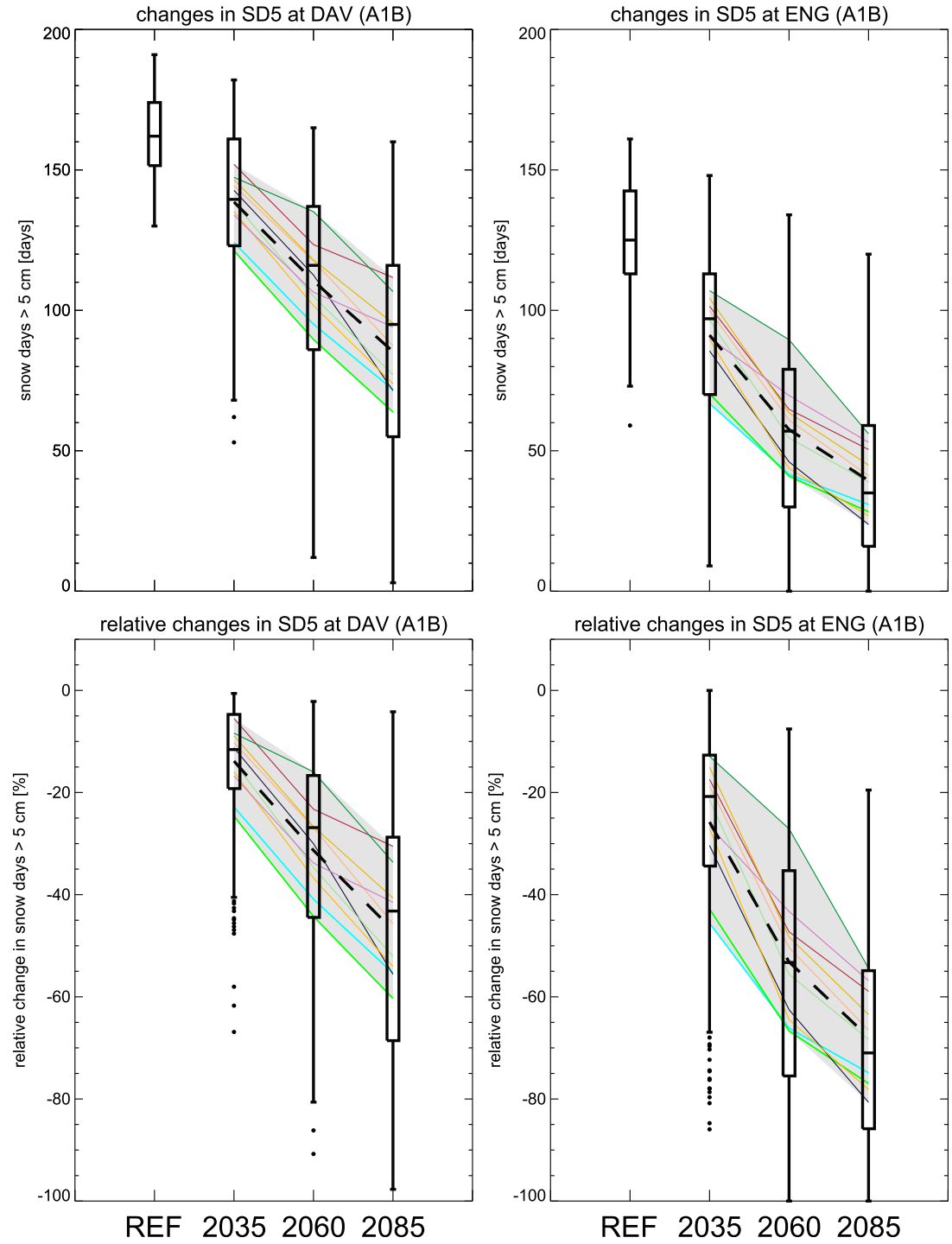

change, i.e., heavily dependent on snow (Gonseth 2013). Ski resorts are therefore highly affected by the projected decrease in snow days (between 15 and $55 \%$ for SD50 until 2060 at high and mid elevations), since the absence of enough natural snow needs to be compensated through the production of artificial snow. This however, besides being highly temperature dependent, implies high water consumption and is very costintensive (Abegg 2013). The investment costs per kilometer artificial ski run are between US\$ 0.75 and 1 million. The annual operating costs are between US\$20,000 and 100,000 per km ski slope (Lang 2009). The abnormally warm winter start 2014/2015 in the Swiss Alps (November and December $2-4{ }^{\circ} \mathrm{C}$ warmer than normal) demonstrated that only ski areas at high elevation and with a powerful artificial snow production network were able to open before Christmas. It can be assumed that the rather small ski resorts at mid elevations, which are already endangered today, will disappear. As the example of the highest investigated station shows, ski areas which have the majority of the slopes above approximately $2000 \mathrm{~m}$ a.s.l. are very likely to be least affected.

The strong decrease in snow days also influences the visual appearance of mountainous resorts (landscape perception). For example, SD5 (Fig. 4) at mid-elevation stations (where the base of most resorts is) is reduced on average to only about 2 months per year (A1B) at the end of the century, but the spread between stations is high (39-85 days). This implies that the economically important Christmas-New Year period might often not be snow covered anymore. Moreover, most of these resorts are projected to experience a noncontinuous snow cover at least every second winter (Fig. 3).

Water resource management is linked with artificial snow production by the fact that the necessary water for the snow production often needs to be pumped up from rivers or hydropower reservoirs once the local reservoirs for snow production are empty. This unfortunately happens at times when natural river flow is at its lowest level, which can cause problems with 
Table 4 Minimum, maximum, and mean relative decrease of the annual mean of the snow indices from the reference period (REF) between the 10 individual models and for the three scenario periods 2035, 2060, and 2085 in the A1B emission scenario

\begin{tabular}{|c|c|c|c|c|c|c|c|c|c|c|c|c|}
\hline \multirow[t]{2}{*}{ Units } & \multicolumn{4}{|l|}{ SD5 } & \multicolumn{4}{|l|}{ SD50 } & \multicolumn{4}{|l|}{ HN1 } \\
\hline & $\begin{array}{l}\text { Mean REF } \\
\text { [days] }\end{array}$ & $\begin{array}{l}2035 \\
{[\%]}\end{array}$ & $\begin{array}{l}2060 \\
{[\%]}\end{array}$ & $\begin{array}{l}2085 \\
{[\%]}\end{array}$ & $\begin{array}{l}\text { Mean REF } \\
\text { [days] }\end{array}$ & $\begin{array}{l}2035 \\
{[\%]}\end{array}$ & $\begin{array}{l}2060 \\
{[\%]}\end{array}$ & $\begin{array}{l}2085 \\
{[\%]}\end{array}$ & $\begin{array}{l}\text { Mean REF } \\
\text { [days] }\end{array}$ & $\begin{array}{l}2035 \\
{[\%]}\end{array}$ & $\begin{array}{l}2060 \\
{[\%]}\end{array}$ & $\begin{array}{l}2085 \\
{[\%]}\end{array}$ \\
\hline WFJ & 283 & & & & 218 & & & & 117 & & & \\
\hline Min decrease & & -3.4 & -9.2 & -14.4 & & -4.2 & -9.6 & -18.3 & & -3.7 & -11.2 & -18.2 \\
\hline Max decrease & & -12.5 & -20.4 & -29.5 & & -14.3 & -27.9 & -38.1 & & -15.9 & -25.6 & -34.9 \\
\hline Mean decrease & & -7.5 & -14.7 & -20.6 & & -7.9 & -17.3 & -26.4 & & -9.6 & -18.6 & -26.0 \\
\hline SBE & 158 & & & & 86 & & & & 52 & & & \\
\hline Min decrease & & -12.0 & -25.7 & -41.6 & & -29.2 & -47.8 & -71.3 & & -13.6 & -23.5 & -35.8 \\
\hline Max decrease & & -40.7 & -63.8 & -78.6 & & -83.3 & -97.4 & -98.8 & & -36.2 & -56.9 & -66.6 \\
\hline Mean decrease & & -21.9 & -40.9 & -58.5 & & -48.9 & -74.9 & -90.2 & & -22.6 & -38.3 & -52.2 \\
\hline ZER & 133 & & & & 31 & & & & 36 & & & \\
\hline Min decrease & & -7.9 & -22.2 & -42.2 & & -28.4 & -76.7 & -93.4 & & -8.4 & -26.6 & -42.6 \\
\hline Max decrease & & -31.3 & -47.3 & -77.2 & & -89.4 & -99.4 & -100.0 & & -28.9 & -46.5 & -62.4 \\
\hline Mean decrease & & -20.4 & -38.2 & -57.3 & & -65.0 & -91.5 & -98.0 & & -19.6 & -38.7 & -53.0 \\
\hline DAV & 161 & & & & 76 & & & & 56 & & & \\
\hline Min decrease & & -5.5 & -16.0 & -30.5 & & -18.8 & -37.0 & -69.7 & & -8.1 & -19.0 & -29.5 \\
\hline Max decrease & & -24.6 & -44.3 & -60.3 & & -63.6 & -89.0 & -96.1 & & -24.0 & -40.0 & -50.7 \\
\hline Mean decrease & & -13.8 & -31.3 & -46.9 & & -37.8 & -68.9 & -85.5 & & -16.0 & -30.1 & -41.3 \\
\hline MVE & 140 & & & & 62 & & & & 43 & & & \\
\hline Min decrease & & -8.3 & -17.8 & -34.8 & & -15.1 & -34.4 & -68.1 & & -10.3 & -22.7 & -34.5 \\
\hline Max decrease & & -30.0 & -51.9 & -72.7 & & -72.3 & -92.3 & -94.6 & & -26.3 & -45.2 & -60.6 \\
\hline Mean decrease & & -19.1 & -40.1 & -56.1 & & -41.3 & -76.6 & -88.5 & & -18.9 & -37.6 & -49.6 \\
\hline ULR & 167 & & & & 114 & & & & 57 & & & \\
\hline Min decrease & & -4.0 & -21.2 & -36.1 & & -19.8 & -51.7 & -76.5 & & -8.5 & -31.1 & -45.0 \\
\hline Max decrease & & -24.4 & -43.5 & -61.4 & & -64.8 & -88.5 & -97.3 & & -32.0 & -48.8 & -61.3 \\
\hline Mean decrease & & -14.6 & -32.5 & -49.4 & & -41.0 & -71.9 & -88.5 & & -21.7 & -40.7 & -53.6 \\
\hline $\mathrm{ABO}$ & 116 & & & & 7 & & & & 47 & & & \\
\hline Min decrease & & -10.8 & -22.9 & -40.3 & & -52.0 & -84.7 & -100.0 & & -9.8 & -20.9 & -31.8 \\
\hline Max decrease & & -33.4 & -56.6 & -73.7 & & -87.6 & -100.0 & -100.0 & & -24.5 & -44.5 & -60.0 \\
\hline Mean decrease & & -22.4 & -45.2 & -59.6 & & -66.0 & -97.3 & -100.0 & & -17.0 & -36 & -48.6 \\
\hline SCU & 123 & & & & 20 & & & & 31 & & & \\
\hline Min decrease & & -11.2 & -24.8 & -47.9 & & -29.8 & -90.1 & -98.3 & & -10.2 & -33.5 & -45.2 \\
\hline Max decrease & & -40.0 & -63.4 & -71.4 & & -97.0 & -100.0 & -100.0 & & -36.8 & -56.6 & -66.1 \\
\hline Mean decrease & & -24.3 & -48.0 & -63.3 & & -65.6 & -97.8 & -99.5 & & -24.0 & -46.4 & -59.0 \\
\hline ENG & 123 & & & & 19 & & & & 46 & & & \\
\hline Min decrease & & -12.9 & -27.1 & -54.4 & & -49.8 & -88.5 & -97.7 & & -13.8 & -26.1 & -43.5 \\
\hline Max decrease & & -45.6 & -66.7 & -80.7 & & -86.8 & -99.8 & -100.0 & & -34.3 & -56.2 & -70.2 \\
\hline Mean decrease & & -25.8 & -53.2 & -67.9 & & -72.1 & -96.4 & -99.4 & & -24.0 & -45.9 & -58.4 \\
\hline PAY & 8 & & & & 0 & & & & 9 & & & \\
\hline Min decrease & & -44.1 & -63.0 & -79.6 & & N/A & N/A & N/A & & -30.0 & -48.3 & -64.2 \\
\hline Max decrease & & -85.8 & -89.6 & -89.6 & & N/A & N/A & N/A & & -63.3 & -75.4 & -84.2 \\
\hline Mean decrease & & -62.8 & -81.4 & -85.6 & & N/A & N/A & N/A & & -43.8 & -64.0 & -75.0 \\
\hline KLO & 9 & & & & 0 & & & & 11 & & & \\
\hline Min decrease & & -32.1 & -80.5 & -83.3 & & N/A & N/A & N/A & & -27.1 & -55.3 & -68.7 \\
\hline Max decrease & & -86.2 & -91.1 & -91.5 & & N/A & N/A & N/A & & -63.9 & -76.6 & -82.8 \\
\hline Mean decrease & & -67.4 & -86.1 & -89.3 & & N/A & $\mathrm{N} / \mathrm{A}$ & N/A & & -45.7 & -67.5 & -77.9 \\
\hline
\end{tabular}

N/A not applicable 


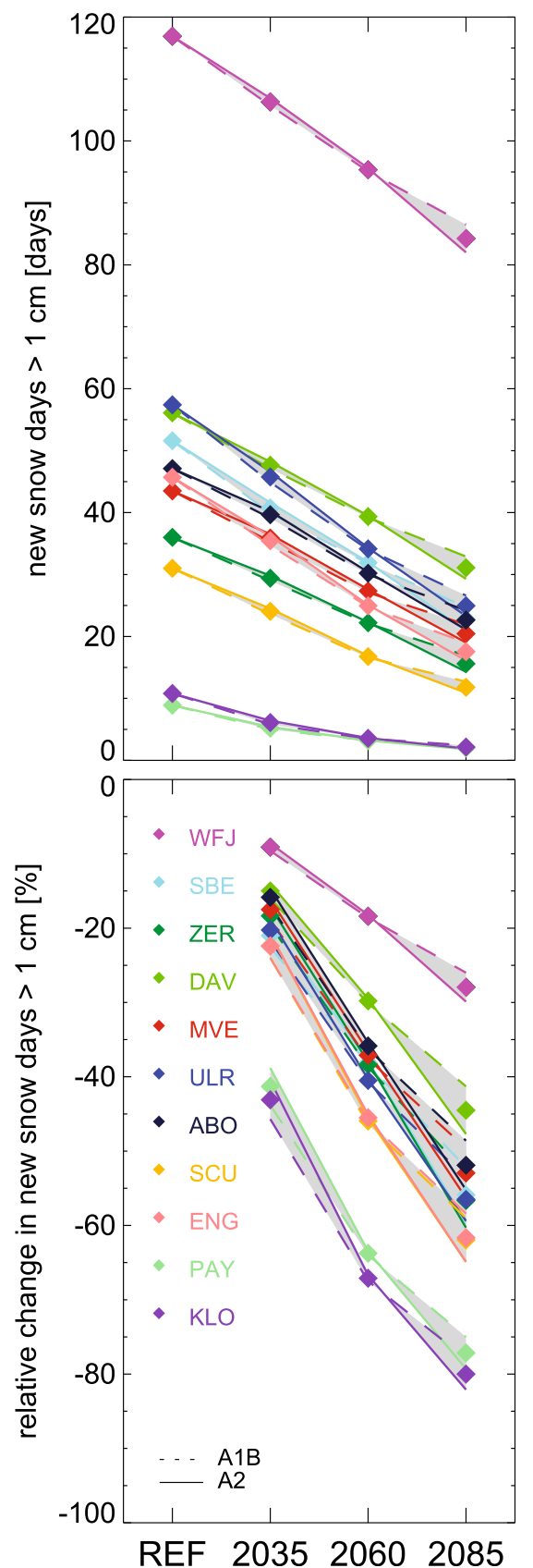

Fig. 6 Absolute mean annual number of new snow days with a threshold greater than $1 \mathrm{~cm}(t o p)$ and relative changes thereof (bottom) for the reference period $(R E F)$ and the three scenario periods 2035, 2060, and 2085. The dashed line corresponds to the A1B emission scenario, whereas the solid line corresponds to the A2 emission scenario. The diamond symbol represents the mean between these two scenarios

environmental regulations or be cost-intensive because hydropower energy production is rare during the winter months. However, this particular problem may become slightly smaller in the future due to an increased winter runoff from Alpine catchments in a warmer climate (Bavay et al. 2009). The presence of snow and ice in the Swiss Alps has therefore a direct bearing on the energy sector. This is important in countries like Austria or Switzerland that depend for more than $60 \%$ on hydropower for electricity generation (Romerio 2002). Nevertheless, the hydropower companies are mostly affected by the decrease in continuous snow cover (Fig. 3) and by the decrease in the mean snow depth (Figs. 1 and 2) especially if dry weather conditions prevail. As shown in our preceding study (Schmucki et al. 2014b), this also implies a similar mean decrease in the snow water equivalent (SWE) of $30 \%$ at high elevation and $80-90 \%$ at mid elevations, which drastically reduces the amount of snow mass available for runoff. Additionally, the peak runoff is projected to be earlier in the season or even suppressed (Addor et al. 2014; Bavay et al. 2009; Köplin et al. 2014). Therefore, it can be assumed that the electricity production through hydropower stations can be increased during the winter season, but reduced in summer due to large reduction in mountain snow cover and glaciers (Schaefli et al. 2007). This implies that the runoff is more consistent throughout the year, which may positively affect hydropower. On the other end, the abovementioned large reduction in summer runoff implies that some mountain rivers may not be able to maintain a sustained discharge during prolonged dry spells anymore (Addor et al. 2014; Haeberli and Beniston 1998; Köplin et al. 2014).

Such changes in the seasonal availability of water resources can have local impacts on water management, such as irrigation of residential zones (drinking water, gardens) or water uses related to tourism (e.g., irrigation of golf courses) or agriculture, especially in southwestern Switzerland (Reynard et al. 2014). Although there is no water stress at the moment in this region, it can be assumed that through the general decrease in SWE, less water will be available during spring, where water demand for irrigation is generally increasing.

One of the main benefits from alpine forests is the protection from natural hazards. In Switzerland, $49 \%$ of the total forest area acts as protective forest, which is maintained by about US\$ 150 Mio public money each year (Hess et al. 2014). Climate change has strong implications on future species composition and on suitable management for climate change adaptation (in particular on the selection of adapted tree species in currently snow-rich areas). A decrease of days with high snow depth (SD50 in Fig. 4) would reduce tree breakage (Nykänen et al. 1997) and reduce the number of avalanches in forested terrain (Bebi et al. 2009; Teich et al. 2012). This would imply a change in forest management from avalanche protection to other priority functions such as rock fall or erosion control. Due to the longevity of trees in mountain forests and subsequent time lags between stand initiation and the provision of relevant ecosystem services of 50 200 years (Motta and Nola 2001; Rammig et al. 2007), the strong decrease of SD50 already has major implications for present-day forest management in such mountain forests. For example, our result based on the reduction of mean SD50 suggests that forest management during stand initiation in the regions of the lowest and/or driest climate stations 
Zermatt, Adelboden, Scuol, and Engelberg could already shift priority from avalanche protection toward other forest functions and/or improved climate change adaptation (Temperli et al. 2012), which includes planting of other tree species.

Snow and ice can cause major problems for transportation infrastructure for communities due to closed roads or airports. The snow removal, road deicing, and road accidents with personal injuries cause major costs each winter. In Germany, for example, the number of such road accidents varies between 6000 in a snow-sparse year like 2011 and almost 20,000 in a snow-abundant year like 2010 (Statistica 2015). Not surprisingly, such traffic accidents are often related to slippery road conditions after snowfall, even in areas where winter road maintenance is performed (e.g., Norrman et al. 2000; Andreescu and Frost 1998). Consequently, the projected absolute (relative) decrease of new snow days (HN1) in the order of $8(80 \%)$ at low elevations and $24(50 \%)$ at mid elevations (Fig. 6) will very likely reduce road accidents, temporary airport closures as well as the costs for winter road maintenance at the end of the century. In the warm and snow-parse year 2007 for example, only $4 \mathrm{HN} 1$ days were counted at low elevations. In this year, the cost for winter maintenance of federal roads in Switzerland were $45 \%$ lower than the average expenses of US\$36 Mio (ASTRA 2015). The above model results ( $80 \%$ reductions in HN1) imply that these costs will be on average almost US\$20 Mio lower in the future due to the rare occurrence of snowfall at the end of the century.

\subsection{Limitations and uncertainty}

These impacts on four socioeconomic sectors are all based on a mean value, which is a product of the climatological mean value of the investigated indices and the mean value of the 10 involved GCM-RCM model chains. Such an analysis based on mean values alone might be enough for winter tourism or winter road maintenance, because higher (lower) costs due to a snow-scare winter can be compensated by the lower (higher) costs in a snow-abundant winter. However, concerning forest management, the situation is much more complicated. It is necessary to consider the full variability of the model results due the slow growth of trees and the sensitivity of some tree species on extreme events. Water management might be somewhere between these two cases, because hydropower may also be able to compensate some extreme years, whereas flood control measures must still be determined by extreme events. Unfortunately, the delta change is not applicable for analyzing extreme events because natural variability is preserved for future climatic conditions as discussed above. Thus, a potential extension of this study to extreme snow indices or future natural variability would require a more sophisticated methodology.

Concerning the uncertainties of the projected temperature increase caused by different GCM-RCM model chains, analysis has shown that the spread between individual models is large (see Figs. 2 and 5 and Table 4). Toward the end of the century, the spread in relative reductions of mean winter snow depth obtained with input of different climate models amounts to $30 \%$ at high and mid elevations, whereas the low elevations show a spread of only $10 \%$. Therefore, the reductions in mean winter snow depth toward the end of the century are most certain at these low elevations. Concerning the mean decrease of the snow indices toward the end of the century, the range between individual models is again lowest at low elevations, followed by high and mid elevations (Table 4). The range of the mean relative reductions of snow indices amounts to roughly $30 \%$ if considered for all scenario periods, elevations, and snow indices. In general, the uncertainty of future snow changes is thereby dominated by the uncertainty from the different GCM-RCM projections, which is in agreement to other studies (Addor et al. 2014; Bosshard et al. 2013). The interquartile range (IQR) of the aggregated values from all models corresponds roughly to the mean IQR of the individual models (not shown), therefore displaying the spread around the median for future climatic conditions (see Figs. 1 and 5). Accordingly, the IQR represents roughly the range of most possible outcomes. Our approach of describing the mean decrease of snow indices as obtained with input from the whole set of available GCM-RCMs can be seen as "best practice" for impact studies because these models form an ensemble and are therefore partly sampling the model uncertainty, although not in a systematic way (Knutti et al. 2010; Tebaldi and Knutti 2007). Moreover, there is no consensus on how to best weigh or eliminate models from the ensemble that perform poorly, and all models are therefore treated equally (CH2011 2011; Knutti et al. 2010; Weigel et al. 2010). Despite these uncertainties, the applied methods are very useful for adaption measures because the used snow model is robust and no selection of specific GCM-RCMs was performed.

\section{Conclusions}

We quantitatively demonstrate the impact of climate change on different snow indices with a physics-based snow model and also account for uncertainties originating from different GCM-RCM model chains. The methodology includes a consideration of increased long-wave radiation under future climatic conditions, which has been most often neglected in earlier studies. Our results corroborate the current physical understanding and the results of other studies in a qualitative manner. The investigated stations span not only a large altitudinal gradient but also represent different snow-climate zones, and we therefore conclude that the results can be expected to be relevant also for neighboring Alpine countries and for other mountain regions with a similar climate. Despite the discrepancies of the projected temperature increase and precipitation 
change between individual GCM-RCMs, snow indices are strongly reduced in all scenario periods and at all elevations, although the projected precipitation increases at some stations. The only exception concerns the high-elevation station Weissfluhjoch, where the decrease in mean winter snow depth is projected to be negligible in the near future and a continuous snow cover might be preserved in all three scenario periods. The mid-elevation stations from 1350 to $1600 \mathrm{~m}$ a.s.l. may only have a continuous snow cover in 7 out of 10 (A1B) or 5 out of 10 winters (A2). The continuous snow cover at midelevation stations from 1000 to $1350 \mathrm{~m}$ a.s.l. may remain only in 4 out of 10 winters or 3 out of 10 winters in the A1B and A2 emission scenario, respectively. At low elevations, it is likely that winters without any snowfall at all occur toward the end of the century. Finally, the choice of the emission scenario has only a minor effect on the future reductions of mean winter snow depth, snow days, or new snow days in the 2085 period, where the A2 emission scenario results in roughly $6 \%$ higher relative reductions.

Overall, the analysis showed a clear decrease of the mean values of the snow indices as expected but reductions in individual years still can be low. In general, a snow-sparse winter of today's climate is likely to become quite average or even snow abundant under future climatic conditions. Moreover, the range of the mean relative reductions of the snow indices between individual GCM-RCMs is high and in the order of $30 \%$. Due to this fact, problems can arise for policy makers, especially concerning forest management or flooding. As a consequence, the results on the mean decrease of the snow indices should be used carefully. These sectors also heavily depend on the evolution of the extreme values, especially for precipitation, under future climatic conditions, which cannot be considered with the delta change method. A more detailed analysis of extreme values is therefore necessary, which should be performed through quantile mapping and transient simulations of individual GCM-RCMs.

Nevertheless, the obtained results will have high implications for different socioeconomic sectors such as hydrology, tourism, or ecology. Since our model is physics based, it would be interesting to apply the methods used in this study to other regions and snow climates. In the next step, we plan to refine our analysis especially for the tourism sector by including simulations of artificial snow production in SNOWPACK. For this, simulations of the spatial distribution of snow (both natural and artificial) are desirable.

Acknowledgments This study was funded by the Swiss National Science Foundation (Grant No. 200021_132200). We strongly acknowledge MeteoSwiss for allocating the meteorological data and the Center for Climate Systems Modeling (C2SM) for providing the CH2011 data.

\section{References}

Abegg (2013) Herausforderung Klimawandel: Chancen und Risiken für Tourismus in Graubünden. Chur

Abegg B, Agrawala S, Crick F, de Montfalcon A (2007) Climate change impacts and adaptation in winter tourism. In: Agrawala $\mathrm{S}$ (ed) Climate change in the European Alps. OECD, Paris, pp 25-60

Addor N, Rössler O, Köplin N, Huss M, Weingartner R, Seibert J (2014) Robust changes and sources of uncertainty in the projected hydrological regimes of Swiss catchments. Water Resour Res 50:75417562. doi:10.1002/2014WR015549

Andreescu M-P, Frost DB (1998) Weather and traffic accidents in Montreal, Canada. Clim Res 9:225-230

ASTRA (2015) Winterdienst auf den Nationalstrassen. http://www.astra. admin.ch/themen/nationalstrassen/02693/index.html?lang=en

Bavay M, Lehning M, Jonas T, Löwe H (2009) Simulations of future snow cover and discharge in Alpine headwater catchments. Hydrol Process 23:95-108. doi:10.1002/hyp.7195

Bavay M, Grünewald T, Lehning M (2013) Response of snow cover and runoff to climate change in high Alpine catchments of Eastern Switzerland. Adv Water Resour 55:4-16. doi:10.1016/j.advwatres. 2012.12.009

Bebi P, Kulakowski D, Rixen C (2009) Snow avalanche disturbances in forest ecosystems - state of research and implications for management. For Ecol Manag 257:1883-1892. doi:10.1016/j.foreco.2009. 01.050

Beniston M (1997) Variations of snow depth and duration in the Swiss Alps over the last 50 years: links to changes in large-scale climatic forcings. Clim Chang 36:281-300

Beniston M (2003) Climatic change in mountain regions: a review of possible impacts. Clim Chang 59:5-31

Blanchet J, Lehning M (2010) Mapping snow depth return levels: smooth spatial modeling versus station interpolation. Hydrol Earth Syst Sci 14:2527-2544. doi:10.5194/hess-14-2527-2010

Blanchet J, Marty C, Lehning M (2009) Extreme value statistics of snowfall in the Swiss Alpine region. Water Resour Res 45:12. doi:10. 1029/2009wr007916

Bosshard T, Kotlarski S, Ewen T, Schaer C, Schär C (2011) Spectral representation of the annual cycle in the climate change signal. Hydrol Earth Syst Sci 15:2777-2788

Bosshard T, Kotlarski S, Zappa M, Schär C (2013) Hydrological climateimpact projections for the Rhine River: GCM-RCM uncertainty and separate temperature and precipitation effects*. J Hydrometeorol 15: 697-713. doi:10.1175/JHM-D-12-098.1

Ceppi P, Scherrer SC, Fischer AM, Appenzeller C (2012) Revisiting Swiss temperature trends 1959-2008. Int J Climatol 32:203-213. doi:10.1002/joc. 2260

CH2011 (2011) Swiss climate change scenarios CH2011. C2SM, MeteoSwiss, ETH, NCCR Climate and OcCC, Zurich, Switzerland

Dilley AC, O’Brien DM (1998) Estimating downward clear sky longwave irradiance at the surface from screen temperature and precipitable water. Q J R Meteorol Soc 124:1391-1401. doi:10.1002/qj. 49712454903

Egli L (2008) Spatial variability of new snow amounts derived from a dense network of Alpine automatic stations. Ann Glaciol 49:51-55

Fischer AM et al (2012) Climate change projections for Switzerland based on a Bayesian multi-model approach. Int J Climatol 32: 2348-2371. doi:10.1002/joc.3396

Gonseth C (2013) Impact of snow variability on the Swiss winter tourism sector: implications in an era of climate change. Clim Chang 119: 307-320

Haeberli W, Beniston M (1998) Climate change and its impacts on glaciers and permafrost in the Alps. Ambio 27:258-265 
Hamon WR (1973) Computing actual precipitation in mountainous areas. Proc. WMO-IAHS Symp on the Distribution of Precipitation in Mountainous Areas, WMO, No. 326, 159-173

Hess J, Schwitter R, Denzler L (2014) Newsletter Schutzwald Schweiz Nr. 8. www.schutzwald-schweiz.ch

IPCC (2007) Climate change 2007: impacts, adaption and vulnerability. Contribution of working group II to the Fourth Assessment Report of the Intergovernmental Panel on Climate Change. Cambridge University Press, Cambridge

IPCC (2014) Climate change 2014: impacts, adaptation, and vulnerability. Contribution of working group II to the Fifth Assessment Report of the Intergovernmental Panel on Climate Change

Knutti R, Collins M, Eyring V, Gleckler PJ, Hewitson B, Mearns L Good practice guidance paper on assessing and combining multi model climate projections. In: IPCC Expert Meeting on Assessing and Combining Multi Model Climate Projections, 2010. p 1

Köplin N, Rößler O, Schädler B, Weingartner R (2014) Robust estimates of climate-induced hydrological change in a temperate mountainous region. Clim Chang 122:171-184. doi:10.1007/s10584-013-1015-x

Krajick K (2004) Climate change: all downhill from here? Science 303: 1600-1602. doi:10.1126/science.303.5664.1600

Lang T (2009) Energetische Bedeutung der Technischen Pistenbeschneiung und Potentiale für Energieoptimierungen. Bundesamt für Energie BFE, Bern

Laternser M, Schneebeli M (2003) Long-term snow climate trends of the Swiss Alps (1931-99). Int J Climatol 23:733-750. doi:10.1002/joc. 912

Lehning M, Bartelt P, Brown B, Fierz C (2002a) A physical SNOWPACK model for the Swiss avalanche warning: part III. Meteorological forcing, thin layer formation and evaluation. Cold Reg Sci Technol 35:169-184

Lehning M, Bartelt P, Brown B, Fierz C, Satyawali P (2002b) A physical SNOWPACK model for the Swiss avalanche warning: part II. Snow microstructure. Cold Reg Sci Technol 35:147-167

Maraun D (2013) Bias correction, quantile mapping, and downscaling: revisiting the inflation issue. J Clim 26:2137-2143. doi:10.1175/ JCLI-D-12-00821.1

Marty C (2008) Regime shift of snow days in Switzerland. Geophys Res Lett 35. doi:10.1029/2008GL033998

Marty C, Meister R (2012) Long-term snow and weather observations at Weissfluhjoch and its relation to other high-altitude observatories in the Alps. Theor Appl Climatol:1-11. doi:10.1007/s00704-0120584-3

Marty C, Philipona R (2000) The Clear-Sky Index to separate clear-sky from cloudy-sky situations in climate research. Geophys Res Lett 27:2649-2652

Moss RH et al. (2010) The next generation of scenarios for climate change research and assessment. Nature 463:747-756. doi:http:// www.nature.com/nature/journal/v463/n7282/suppinfo/ nature 08823 S1.html

Motta R, Nola P (2001) Growth trends and dynamics in sub-alpine forest stands in the Varaita Valley (Piedmont, Italy) and their relationships with human activities and global change. J Veg Sci 12:219-230. doi: $10.2307 / 3236606$

Norrman J, Eriksson M, Lindqvist S (2000) Relationships between road slipperiness, traffic accident risk and winter road maintenance activity. Clim Res 15:185-193

Nykänen M-L, Peltola H, Quine C, Kellomäki S, Broadgate M (1997) Factors affecting snow damage of trees with particular reference to European conditions. Silva Fenn 31:193-213

Peng S, Piao S, Ciais P, Fang J, Wang X (2010) Change in winter snow depth and its impacts on vegetation in China. Glob Chang Biol 16: 3004-3013. doi:10.1111/j.1365-2486.2010.02210.x
Rammig A, Bebi P, Bugmann H, Fahse L (2007) Adapting a growth equation to model tree regeneration in mountain forests. Eur $\mathrm{J}$ Forest Res 126:49-57. doi:10.1007/s10342-005-0088-0

Reynard E et al (2014) Interdisciplinary assessment of complex regional water systems and their future evolution: how socioeconomic drivers can matter more than climate. Wiley Interdiscip Rev: Water 1:413-426. doi:10.1002/wat2.1032

Romerio (2002) European electrical systems and Alpine hydro resources. Gaia 3:200-202

Schaefli B, Hingray B, Musy A (2007) Climate change and hydropower production in the Swiss Alps: quantification of potential impacts and related modelling uncertainties. Hydrol Earth Syst Sci Discuss 11: 1191-1205

Scherrer SC, Appenzeller C (2006) Swiss Alpine snow pack variability: major patterns and links to local climate and large-scale flow. Clim Res 32:187-199

Scherrer SC, Appenzeller C, Laternser M (2004) Trends in Swiss Alpine snow days: the role of local- and large-scale climate variability. Geophys Res Lett 31. doi:10.1029/2004GL020255

Schmucki E, Marty C, Fierz C, Lehning M (2014a) Evaluation of modelled snow depth and snow water equivalent at three contrasting sites in Switzerland using SNOWPACK simulations driven by different meteorological data input. Cold Reg Sci Technol 99:27-37. doi:10.1016/j.coldregions.2013.12.004

Schmucki E, Marty C, Fierz C, Lehning M (2014b) Simulations of 21st century snow response to climate change in Switzerland from a set of RCMs. Int J Climatol. doi:10.1002/joc.4205

Statistica (2015) Anzahl der Straßenverkehrsunfälle mit Personenschaden durch Schnee und Glatteis in Deutschland in den Jahren 2010 bis 2013. Hamburg

STV (2014) Schweizer Tourismus in Zahlen 2013. Struktur und Branchendaten, Bern

Tebaldi C, Knutti R (2007) The use of the multi-model ensemble in probabilistic climate projections. Philos Trans R Soc A Math Phys Eng Sci 365:2053-2075

Teich M, Marty C, Gollut C, Grêt-Regamey A, Bebi P (2012) Snow and weather conditions associated with avalanche releases in forests: rare situations with decreasing trends during the last 41 years. Cold Reg Sci Technol 83-84:77-88. doi:10.1016/j.coldregions. 2012.06.007

Temperli C, Bugmann H, Elkin C (2012) Adaptive management for competing forest goods and services under climate change. Ecol Appl 22:2065-2077. doi:10.1890/12-0210.1

Unsworth MH, Monteith JL (1975) Long-wave radiation at the ground I. Angular distribution of incoming radiation. Q J R Meteorol Soc 101: 13-24. doi:10.1002/qj.49710142703

van der Linden P, Mitchell JFB (eds) (2009) ENSEMBLES: climate change and its impacts at seasonal, decadal and centennial timescales; summary of research and results from the ENSEMBLES project. Met Office Hadley Centre, Exeter, UK

van Vuuren D et al (2011) The representative concentration pathways: an overview. Clim Chang 109:5-31. doi:10.1007/s10584-011-0148-z

Weigel AP, Knutti R, Liniger MA, Appenzeller C (2010) Risks of model weighting in multimodel climate projections. J Clim 23:4175-4191. doi:10.1175/2010JCLI3594.1

Wipf S, Stoeckli V, Bebi P (2009) Winter climate change in alpine tundra: plant responses to changes in snow depth and snowmelt timing. Clim Chang 94:105-121. doi:10.1007/s10584-009-9546-x

Zubler E, Scherrer S, Croci-Maspoli M, Liniger M, Appenzeller C (2014) Key climate indices in Switzerland; expected changes in a future climate. Clim Chang 123:255-271. doi:10.1007/ s10584-013-1041-8 